treatment group. The initial $\left[\mathrm{H}^{+}\right]$was significantly higher in the multiple treatment group $(p<0.05)$, thus rejecting this null hypothesis.

\section{Discussion}

The cause and manifestations of CMP in this group are consistent with previously-reported series from other hyperbaric centres. ${ }^{9}$ The key finding is the difference in $\left[\mathrm{H}^{+}\right]$at admission between the single and multiple treatment groups. This is consistent with the mechanism of toxicity of CMP.

Initial $\left[\mathrm{H}^{+}\right]$may be an index of severity of poisoning because of its effect on cellular metabolism due to binding of carbon monoxide to intracellular oxygen carrying proteins, for example cytochromes. Despite the small numbers, a significant association with acidaemia on admission and the need for multiple treatments was found and should be investigated further.

Previous studies have found that $\mathrm{COHb}$ does not correlate well with severity of poisoning. ${ }^{6}$ The reasons include: timing of measurement, rate of elimination, duration of exposure, and concentration of carbon monoxide in the inspired gas. In our patients there was a trend towards $\mathrm{COHb}$ being predictive of the need for multiple treatments but statistical significance was not reached.

The need for more than one treatment is only a surrogate measure of severity. The assessment of outcome of patients with CMP, particularly those due to deliberate poisoning, is difficult and may not necessarily be correlated with the severity of poisoning. Outcome may be confounded by premorbid state, cognitive reserve, and the response to treatment. It is therefore equally valid to use the amount of treatment required, so long as indications for repeat treatments are consistent and were not influenced by the initial $\left[\mathrm{H}^{+}\right]$. During the period of this study the initial $\left[\mathrm{H}^{+}\right]$was not one of the indications for repeat treatment. A predictor of the amount of treatment needed in itself may be helpful.
The management of CMP is based primarily on the clinical condition of the patient, however some recommend hyperbaric oxygen on the basis of a high $\mathrm{COHb}$ concentration at presentation. Acidaemia may give an additional measure of severity of poisoning and, in this study, correlated better with the need for multiple treatments than did $\mathrm{COHb}$. More specific measures of cellular dysfunction, such as lactate, should also be considered for further investigation. These data alone do not suggest that patients with an initial metabolic acidosis require multiple treatments, however patients with such an acidosis must be considered to have significant poisoning even if the $\mathrm{COHb}$ is low.

\section{Conclusion}

Initial assessment of the patient with CMP should include a full history and clinical examination, $\mathrm{COHb}$ concentration (confirming exposure), and arterial $\left[\mathrm{H}^{+}\right]$. Future studies of carbon monoxide poisoning should include data on initial $\left[\mathrm{H}^{+}\right]$.

We acknowledge Dr Roger Pethybridge, Institute of Naval Medicine for statistical advice.

1 Broome JR, Pearson RR, Skrine H. Carbon monoxide poisoning, forgotten not gone! Brf Hosp Med 1988;39:298305.

2 Office of Population Censuses and Surveys. Mortality statistics by cause England and Wales. London: HMSO, 1992. Series DH2 No 19.

3 Raphael JC, Elkharrat D, Jars-Guincestre MC, et al. Trial of normobaric and hyperbaric oxygen for acute carbon monoxide intoxication. Lancet 1989;ii:414-19.

4 Thom SR, Taber RL, Mendiguren II, et al. Delayed neuropsychologic sequelae after carbon monoxide neuropsychologic sequelae after carbon monoxide poisoning: prevention by treatment with

5 Myers RAM, Snyder SK, Emhoff TA. Sub-acute sequelae of Myers RAM, Snyder SK, Emhoff TA. Sub-acute sequelae of
carbon monoxide poisoning. Ann Emerg Med 1985;14:

1163-7.

6 Smith JS, Brandon S. Morbidity from acute carbon monoxide poisoning at three-year follow-up. $B M \mathcal{F}$ 1973;i:318-21.

7 Norkool DM, Kirkpatrick JN. Treatment of acute carbon monoxide poisoning with hyperbaric oxygen: a review of 115 cases. Ann Emerg Med 1985;14:1168-71.

8 Goldbaum LR, Orellano T, Dergal E. Mechanism of the toxic action of carbon monoxide. Ann Clin Lab Sci 1976;6: $372-6$.

9 Gorman DF, Clayton D, Gilligan JE, et al. A longitudinal study of 100 consecutive admissions for carbon monoxide poisoning to the Royal Adelaide Hospital. Anaesth Intensive Care 1992;20:311-16.

10 Siegel S. Non-parametric statistics for the behavioural sciences. New York: McGraw-Hill, 1956.

\title{
British Hyperbaric Association carbon monoxide database, 1993-96
}

\author{
Martin R Hamilton-Farrell
}

Hyperbaric Unit, Whipps Cross Hospital, London E11 1NR

Correspondence to: Dr Hamilton-Farrell, Consultant Anaesthetist, Director of Hyperbaric Unit.
Abstract

Objectives-To study the referral pattern of patients, poisoned with carbon monoxide and subsequently transferred to British hyperbaric oxygen facilities, from April 1993 until March 1996 inclusive.

Methods-A standard dataset was used by hyperbaric facilities within the British Hyperbaric Association. The data on each patient were sent in confidence to the
Hyperbaric Unit at Whipps Cross Hospital for analysis. The epidemiology of poisoning and the population studied were analysed. Times of removal from exposure, referral to a hyperbaric facility, arrival at the hyperbaric facility, and start of treatment were recorded. Data on the outcome of the episode were documented in one of the contributing facilities. 
Results -575 patients exposed to carbon monoxide were reported as being referred to British hyperbaric facilities in the three years, the busiest facilities being in London and Peterborough. The proportions of accidental and non-accidental exposures were 1:1.05. Of the accidental exposures, central heating faults were responsible in $71.5 \%$ of cases $(n=206)$. Smoke inhalation from fires was responsible for a further $13.5 \%(n=39)$. The mean delay to arrival in a hyperbaric oxygen facility was 9 hours and 15 minutes after removal from exposure. Recovery after treatment was sometimes incomplete.

Conclusions-The reported pattern of referral was regionally weighted towards the south east of England. Smoke inhalation victims were often not referred for hyperbaric oxygen treatment. The delay to treatment was multifactorial; and the mean delay was well in excess of six hours. There is room for improvement in the consistency and speed of referral. Treatment schedules require standardisation. A central advice and referral service would be helpful.

(F Accid Emerg Med 1999;16:98-103)

Keywords: carbon monoxide poisoning; hyperbaric oxygen treatment; epidemiology

The treatment of severe carbon monoxide poisoning (CMP) with hyperbaric oxygen is well established. ${ }^{2}$ Late neurological complications may arise from such poisoning. ${ }^{3}$ The prevention of these sequelae is an important indication for the use of hyperbaric oxygen. ${ }^{45}$ The provision of hyperbaric oxygen for CMP in Britain was uncoordinated until informal discussions began in 1990. The British Hyperbaric Association (BHA) was founded in that year, and formally constituted in 1993. All hyperbaric facilities providing this service in the UK became members of the BHA.

From the outset of this new cooperation, the pattern of referrals was not uniform. Although some referrals were made directly from accident and emergency departments, many were perceived as being made after consultation with one or other of the National Poisons Information Service centres in various cities. The availability of hyperbaric oxygen treatment for severe CMP was also widely unknown to potential referring hospitals. There was no standardised treatment regimen for the use of hyperbaric oxygen, or any systematic follow up of those treated.

In order to analyse the epidemiology of this condition, the efficiency of referral and transport arrangements, and the treatment and possible outcomes achieved in hyperbaric units, a standard dataset was adopted at Whipps Cross Hospital in 1992. It was adopted by the BHA as a whole in 1993. In April 1993, members of the association began sending completed data- base forms to the Hyperbaric Unit at Whipps Cross Hospital for analysis.

The first three years of this survey encompassed the publication of a code of good working practice for the operation and staffing of hyperbaric chambers for therapeutic purposes (1994), ${ }^{6}$ a gazetteer of members of the BHA (1995), ${ }^{7}$ and guidelines on fire safety (1994) and electrical safety (1995) in hyperbaric facilities. ${ }^{89}$ The development of new hyperbaric facilities was thereafter anticipated, and increased awareness of hyperbaric medicine as a whole was expected.

It was perceived that the period April 1993 until March 1996 would establish a pattern for practice against which further developments could be usefully compared. Specifically, it was suspected that there was a long time delay between the removal of the patient from carbon monoxide exposure and arrival in a hyperbaric facility.

\section{Methods}

The dataset used was developed from clinical practice and observation at Whipps Cross Hospital, then the busiest single hyperbaric facility for emergency referrals in the UK, during the years 1989-92. It was used instead of medical case notes in some centres. It recorded times of removal from exposure to carbon monoxide, referral for hyperbaric oxygen, arrival at the hyperbaric facility, and start of hyperbaric oxygen treatment. It recorded details of treatment schedules and, in some instances, follow up.

Data were contributed by 10 hyperbaric facilities from different regions of the UK. The other members of the BHA treated very few cases of CMP. There was under-reporting from some contributors. Copies of actual case notes were not accepted, and were destroyed if submitted. Completed forms contained patient names and addresses, and were retained in the Hyperbaric Unit at Whipps Cross Hospital or in that hospital's Department of Clinical Audit. The retention of such data was covered by the General Medical Council's guidance on confidentiality (October 1995), and retrospective approval was obtained by Redbridge and Waltham Forest Health Authority ethics committee.

Data analysis was carried out by the Department of Clinical Audit at Whipps Cross Hospital, with the knowledge and permission of all contributors. Further analysis of delay times, treatment schedules, and outcomes was carried out by the author. Presentations of each year's data were made by the author to the annual meetings of the BHA (held in September/October of each year).

\section{Results}

SOURCES OF DATA

Whipps Cross Hospital and Peterborough District Hospital reported the largest caseloads, with similar increases between 1993/94 and 1994/95 (fig 1). In 1995/96, Peterborough's caseload continued to rise, while that of Whipps Cross Hospital declined. These two centres consist of monoplace (one person) 


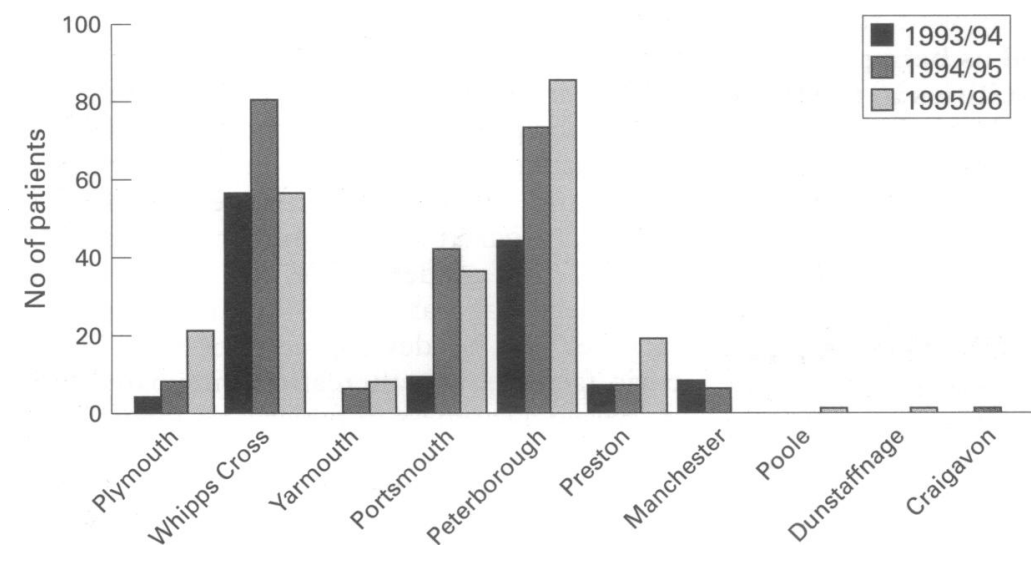

Figure 1 Sources of data.

Table 1 Population studied

\begin{tabular}{lllll}
\hline & $1993 / 94$ & $1994 / 95$ & $1995 / 96$ & Totals \\
\hline Total cases accepted & 128 & 219 & 228 & 575 \\
Refused treatment & 1 & 2 & 1 & 4 \\
Curtailed treatment & 6 & 9 & 10 & 25 \\
Died during treatment & 2 & 0 & 0 & 2 \\
\hline
\end{tabular}

chambers, funded by the NHS. North Manchester Infirmary is similar in structure. The remaining hyperbaric facilities are multiplace (walk-in) chambers, capable of receiving critically ill patients who may require invasive monitoring. Reporting from some centres was incomplete.

\section{POPULATION STUDIED}

The annual caseload reported nearly doubled between 1993/94 and 1994/95 (table 1). Curtailed treatments included cases where the patient suffered claustrophobia or another complication of hyperbaric oxygen treatment. The two patients who died had been retrieved from a house fire, and were moribund on arrival at the hyperbaric unit.

\section{MODE OF EXPOSURE}

A total of 292 cases (51.0\%) were accidental; 280 cases were non-accidental (49.0\%); in three cases, the cause was not recorded. The ratio of accidental to non-accidental cases was therefore 1.05:1. Of the accidental cases, 81 were exposed continuously or intermittently for more than 24 hours.

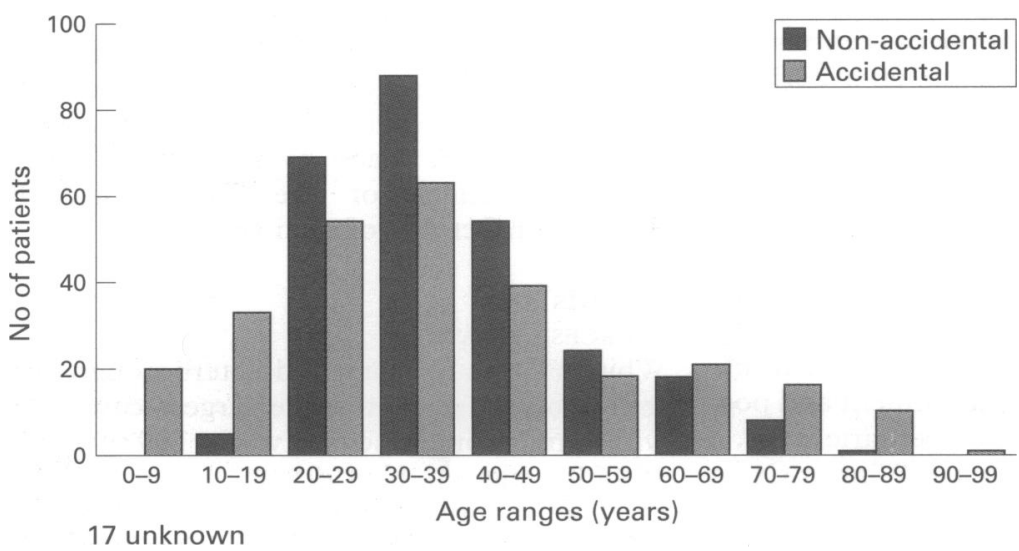

Figure 2 Ages (years) of patients: accidental and non-accidental exposure.

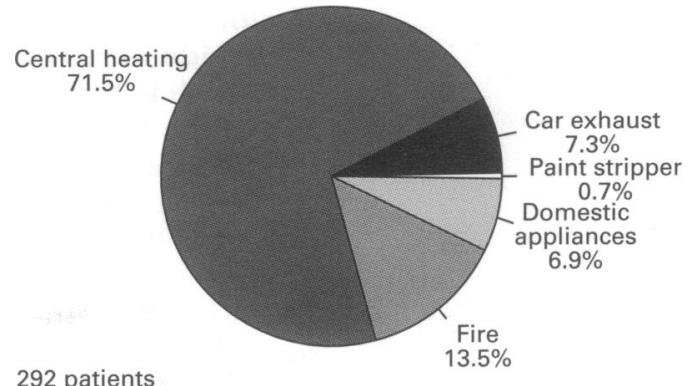

292 patients

Figure 3 Sources of accidental exposure.

AGE RANGES

The majority of non-accidental cases were between 20 and 49 years old. In contrast, the accidental group included patients at the extremes of youth and age (fig 2). Mean age for the whole population was 38.2 years; for the accidental group 37.2 years; and for the non-accidental group 39.3 years.

Of the accidental cases, $150(51.9 \%)$ were male and $139(48.1 \%)$ were female. Of the non-accidental cases, $237(85.3 \%)$ were male and $41(14.7 \%)$ were female.

\section{SOURCES OF ACCIDENTAL EXPOSURE}

Central heating sources were entirely from blocked or leaking exhaust systems (leading to exposure to carbon monoxide after combustion). Accidental car exhaust exposure was principally from accidentally running the car engine inside an enclosed space (that is garage). Paint stripper fumes containing methylene chloride would be metabolised by the liver to produce carbon monoxide. Domestic appliances included gas fires and other combustion devices, such as generators. Fire exposure included not only carbon monoxide, but also other constituents of smoke such as cyanide (fig 3).

\section{PRESENTATION BY MONTH}

While the presentation of non-accidental cases was continuous throughout the year, accidental cases predominated in the winter months (November to February inclusive). Peaks occurred during individual winter months where there was a period of severe cold (fig 4).

\section{DELAY TO PATIENT DELIVERY}

The mean delay to delivery from time of removal from exposure to carbon monoxide was in excess of six hours in all three years. The mean for the whole study period was 9 hours and 15 minutes. Although some individual cases were treated after delays of several days, the mode for the three years was 5 hours. Actual delay times (where available) are illustrated in fig 5 . Sixteen patients arrived at hyperbaric facilities more than 30 hours after removal from carbon monoxide. These included one patient each at $33,34,35,36,38$, $39,42,44,49,87,95,98$, and 99 hours and three patients at 102 hours.

For the year 1995/96, the mean delay could be categorised as in table 2 .

TREATMENT SCHEDULES

Each hyperbaric oxygen facility used its own treatment schedules, resulting in great variabil- 


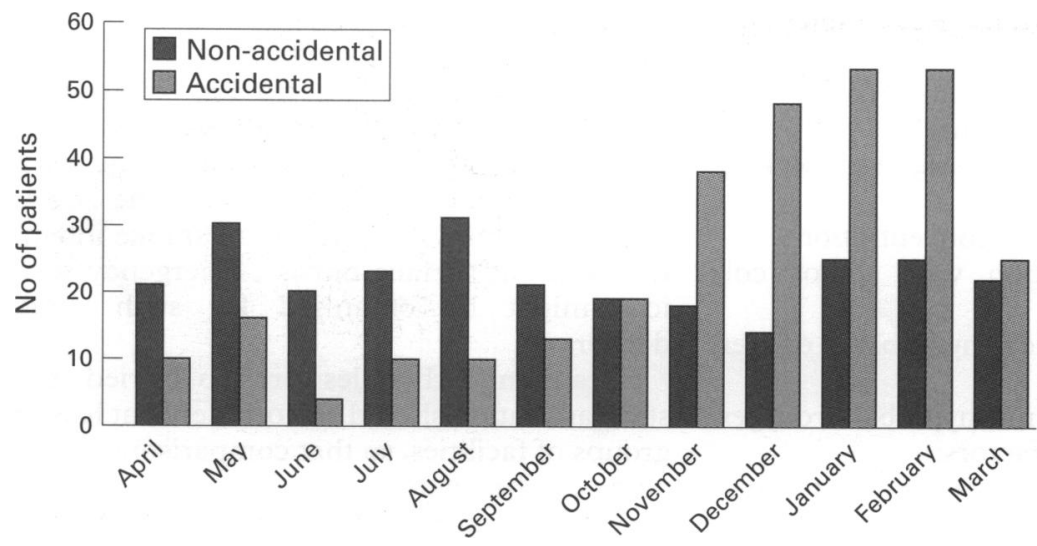

Figure 4 Presentation by month.

Table 2 Mean delay from removal from carbon monoxide until arrival at hyperbaric facility (1995/96 only)

\begin{tabular}{lll}
\hline & Time $(\mathrm{min})$ & $\begin{array}{l}\text { Cases where } \\
\text { data } \\
\text { available }\end{array}$ \\
\hline $\begin{array}{l}\text { Removal from carbon monoxide } \\
\quad \text { until call to hyperbaric facility }\end{array}$ & 272 & 125 \\
$\begin{array}{l}\text { Call to hyperbaric facility until } \\
\quad \text { arrival at facility }\end{array}$ & 287 & 123 \\
$\begin{array}{l}\text { From arrival at facility until start of } \\
\text { treatment }\end{array}$ & 67 & 143 \\
\hline
\end{tabular}

ity; $100 \%$ oxygen was generally used. Pressures never exceeded 3 atmospheres absolute; and durations never exceeded 3 hours and 40 minutes; this is the time taken in the United States Air Force carbon monoxide treatment table used at Whipps Cross Hospital. In this table, air breaks were provided periodically to prevent oxygen toxicity. Other treatment schedules used included Royal Navy Decompression Table 60, and US Navy Decompression Table 5,2 hours at 2 atmospheres absolute (ATA), 3 hours at 1.5 ATA, and $20 \mathrm{~min}$ at 2.8 ATA followed by 1 hour at 2.5 ATA. Patients tended to be retreated in case of failure to resolve symptoms and signs after the first exposure to hyperbaric oxygen, until signs and symptoms resolved or stabilised.

FOLLOW UP OF PATIENTS

Patients attending the Whipps Cross Hospital Hyperbaric Unit were invited to return between eight and 12 weeks after their treatment for follow up assessment. Of the 50 patients (26\%) who did so during the period of the

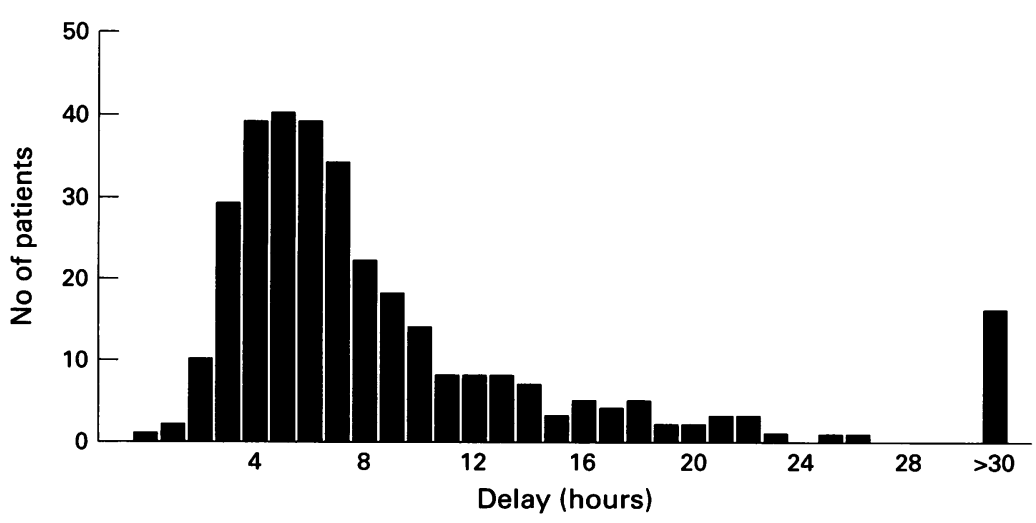

326 patients' data available

Figure 5 Delay (hours) to patient delivery. study, 37 complained of further symptoms after discharge, including memory loss, headaches, and fatigue. While 44 were normal on neurological examination, six were found to have persistent short term memory loss. Post-treatment symptomatology was not significantly different between acutely and chronically poisoned patients.

\section{Discussion}

This is the first national survey of hyperbaric oxygen treatment activity in the context of CMP. The organisation of advice and referral for cases of CMP in the UK has already changed since the time period of this study, as a national telephone number (based in the South West Regional Hyperbaric Medical Centre, Plymouth) has been in operation since the spring of 1996. New hyperbaric facilities are being developed in various locations.

In the period of this study, the number of referrals was similar in the second and third years, suggesting that the caseload was stabilising after the establishment of the study. Patient numbers were few in comparison with activity in northern France, where the Lille hyperbaric facility is known to treat more than 300 cases annually from the Pas de Calais and Nord departments alone.

Although there was under-reporting from some centres, the preponderance of activity in Peterborough and London may have been due to the consistency of the advice from the New Cross Hospital Poisons Unit, where the indications for hyperbaric oxygen were given as any one of the following, similar to international consensus $^{10}$ :

- Loss of consciousness at any stage since exposure to carbon monoxide.

- Neurological symptoms or signs at the referring hospital other than a simple headache.

- Pregnancy.

- Myocardial ischaemia or arrhythmias.

- Carboxyhaemoglobin (COHb) $>25 \%$.

In other parts of the UK, advice may not have been the same as this.

The distribution of cases between accidental and non-accidental exposure was different from that in North America, where many referrals for hyperbaric oxygen treatment are direct from the scene of a fire, with smoke inhalation. The main hyperbaric facility in New York City, for instance, is organised by the fire department, as also is much of the American ambulance service. Smoke inhalation is a common feature of admission to British burns units; however, there is no hyperbaric oxygen facility within a burns unit in the UK. Cases referred to hyperbaric oxygen units therefore tend not to have significant surface burns.

The monthly distribution of referrals confirms the consistency of non-accidental cases throughout the year. Accidental cases were sometimes part of mass casualties, from large families or from workplace accidents. In some of these instances, patients were sent to different hyperbaric facilities; and sometimes, patients requiring hyperbaric oxygen treatment could not receive it. 
The delay to referral includes several factors:

- Efficiency of delivery by emergency services.

- Identification of the diagnosis (sometimes obscured in chronic exposure).

- Recognition of severe cases, and seeking advice.

- Obtaining COHb blood concentrations.

- Confirmation of action with senior colleagues.

- Identification of a local hyperbaric oxygen facility.

The delay to arrival in a hyperbaric oxygen facility includes several factors:

- Organisation of ambulance or other transport.

- Preparation of the patient for transport.

- The duration of the journey.

The time taken for patient assessment and preparation might also include:

- Mobilisation of the hyperbaric oxygen facility and its staff.

- Preparation of external ears for pressure changes (that is clearance of cerumen, or tympanotomy).

- Obtaining a chest $x$ ray.

It is possible that referral could be accelerated within accident and emergency departments by systematic guidance on the relevance of loss of consciousness (despite subsequent recovery), the neurological signs to be sought, and the relative unreliability of $\mathrm{COHb}$ blood concentrations in determining the severity of poisoning. ${ }^{11}$ Reliable information on the local availability of hyperbaric oxygen facilities would also avoid wastage of time. The BHA has now published its gazetteer of member facilities, including clinical capabilities.

Delivery times might be shortened by the use of helicopter transport in some cases. However, the mobilisation of a helicopter in some parts of the UK may take as long as the rapid dispatch of a wheeled ambulance. Journey times may be reduced by helicopter transport, especially considering the geographical distribution of British hyperbaric oxygen facilities. A study in northern Norway, for instance, recorded a mean reduction in journey time for trauma cases delivered to the University Hospital in Tromso, of 69 minutes, as compared with road transport. ${ }^{12}$ Comparisons with metropolitan areas of Britain, however, may be not be valid.

This study, conducted effectively without the use of helicopter transport, shows that delay times before a referral to a hyperbaric oxygen facility is initiated are similar to delay times for the journey itself (table 2). Whether a helicopter is used or not, many other components of delay can be reduced or eliminated. The most rapid delivery of patients to hyperbaric oxygen units would be directly from the scene of exposure, bypassing accident and emergency departments altogether. This is already common practice with diving related accidents. It has already been established, for the Royal London Helicopter Emergency Medical Service, that there is a need for a system to grade all 999 calls in the ambulance control room, so that the appropriate pre-hospital response can be directed to each patient. ${ }^{13}$ If there were nationally accepted criteria for selection of patients for hyperbaric oxygen treatment, and if the diagnosis was obvious (as in the parasuicidal patient in a vehicle where the engine was still running, or a victim of smoke inhalation without surface burns), emergency services might be organised for such direct delivery.

Treatment schedules are so varied that standardisation should be considered at least in groups of facilities, so that comparisons of outcome can be made.

Outcome analysis, as far as it has been conducted, reveals a common pattern of continuing headache and general ill health for several days after hyperbaric oxygen treatment. The persistence of memory loss in particular suggests that the removal of the carbon monoxide from blood and central nervous system at the time of treatment does not resolve the pathology of the poisoning. However, the attendance rate for follow up was low. It is possible that patients would wish to attend specifically because they had continuing symptoms: thus, the analysis of symptoms might not reflect the population as a whole.

If the principal purpose of this treatment is to prevent late complications of poisoning, it is necessary for follow up of these patients to be conducted systematically by independent clinicians aware of the common features of such sequelae. The work of Thom et al provides a useful framework, and relies on a battery of neuropsychometric tests conducted immediately after treatment and 28 days later. ${ }^{14}$

This report gives an account of the use of hyperbaric treatment for CMP in the UK in the mid-1990s. Many changes are occurring in hyperbaric medicine which may be documented in future years by comparison with this database.

The BHA adopted the dataset at an early stage in its formation, establishing a new cooperation between British hyperbaric oxygen facilities. Publications of the BHA (including references 7, 8, and 9) are available from: British Hyperbaric Association, North Sea Medical Centre, Gorleston, Great Yarmouth NR31 6SG.

1 Norkool DM, Kirkpatrick JN. Treatment of acute carbon moxide poironing with 115 cases. Ann Emerg Med 1985;14:1168-71.

2 Sloan EP, Murphy DG, Hart R, et al. Complications and protocol considerations in carbon monoxide poisoned patients who require hyperbaric oxygen therapy. Ann Emerg Med 1989;18:629-34.

3 Choi IS. Delayed neurological sequelae in carbon monoxide intoxication. Arch Neurol 1983;40:433-5.

4 Myers RAM, Snyder SK, Emhoff TA. Subacute sequelae of carbon monoxide poisoning. Ann Emerg Med 1985;14 1163-7.

5 Mathieu D, Nolf M, Durocher A, et al. Acute carbon monoxide poisoning risk of late sequelae and treatmen by hyperbaric oxygen. $f$ Toxicol Clin Toxicol 1985;23: 315-24.

6 Cox R, chairman. Working Party of the Faculty of Occupational Medicine. $A$ code of good working practice for the operation and staffing of hyperbaric chambers for theraperatic tion and staffing of hyperbaric chambers for therapeutic purposes. London: Faculty of Occupatio

7 Colvin A, chairman. Working Party of the British Hyperbaric Association. Gazetteer of members. Aberdeen: British baric Association. Gazetteer of

8 Gough-Allen R, chairman. Working Party of the British

Hyperbaric Association. Fire safety. Aberdeen: British Hyperbaric Association. Fire
Hyperbaric Association, 1994. 
9 Ross J, chairman. Working Party of the British Hyperbaric Asociation. Electrical safery. Aberdeen: British Hyperbaric Asociation. Electrical

10 European Committee for Hyperbaric Medicine. First European consensus conference on hyperbaric medicine: reports and pean consensus conference on hyperbaric medicine: reports and
recommendations, 1995. (Conference held in Lille, France, recommendations,

11 Myers RAM, Britten JS. Do arterial blood gases have value in prognosis and treatment decisions in carbon monoxide poisoning? Crit Care Med 1989;17:139-42.
12 Hotvedt $\mathrm{R}$, Kristiansen IS, Forde $\mathrm{OH}$, et al. Which groups of patients benefit from helicopter evacuation? Lancet 1996; 347:1362-6.

13 Coats TJ, Newton A. Call selection for the Helicopter Emergency Medical Service: implications for ambulance Emergency Medical Service: implicatio

14 Thom SR, Taber RL, Mendiguren II, et al. Delayed neurological sequelae after carbon monoxide poisoning: prevention by treatment with hyperbaric oxygen. Ann Emerg Med 1995;25:474-80.

\section{Medic 1 Trust Fellowship}

The Medic 1 Trust Fellowship is awarded to facilitate education or research in the field of accident and emergency medicine and may be used for associated travel.

The Fellowship is awarded to a doctor or nurse currently working in the field of accident and emergency medicine.

The value of the award will be a maximum of $£ 2500$.

A maximum of one medical scholarship and one nursing scholarship will be made every year. Applications must be received by 31 October 1999 .

For further information please write to: Chairman of the Medic 1 Trust, c/o Alex Morison \& Co, WS, Solicitors, Erskine House, 68 Queen Street, Edinburgh EH2 4NN. 